\title{
LIPID A, VARIOUS FATTY ACIDS, AND THEIR DERIVATIVES AS PROTON CONDUCTORS IN MEMBRANE VESICLES FROM ESCHERICHIA COLI
}

\author{
JIUNU-SHYONG LAI, ${ }^{1}$ SHIN-ICHI OKUDA, AND HAJIME TAKAHASHI \\ Department of Agricultural Chemistry, Faculty of Agriculture, \\ Tohoku University, Sendai 980
}

(Received March 18, 1977)

The mechanism of inhibition by lipid A, various fatty acids, or their derivatives on the transport activities of membrane vesicles from Escherichia coli was studied. Various fatty acids and lauryl alcohol dramatically enhanced the proton permeability of membrane vesicles, potently inhibited the uptake of triphenylmethylphosphonium ion by the membrane vesicles, and severely inhibited the uptake of serine driven by an artificial membrane potential introduced by $\mathrm{K}^{+}$-diffusion via valinomycin. Lipid A and methyl laurate also acted similarly to fatty acids although to a lesser extent.

It was also found that the inhibition of transport activities by lipid A and fatty acids was partially recovered by the addition of bovine serum albumin. Bovine serum albumin removed fatty acid from fatty acidtreated membrane vesicles and reduced the proton permeability compared to the treated membrane vesicles.

These results indicated that lipid A, fatty acids, and their derivatives acted as proton conductors of membrane vesicles. The proton potential (interior negative) produced by electron transport systems or by $\mathrm{K}^{+}$valinomycin was abolished in the presence of these compounds. For this reason, neither succinate nor amino acids could be accumulated by membrane vesicles in the presence of lipid A, fatty acids, or their derivatives.

In the preceding papers (1-2), we have shown that lipid $\mathrm{A}$ and fatty acids severely inhibited the accumulation of succinate or amino acids (serine, glycine, alanine, and leucine) by the membrane vesicles of Escherichia coli which coupled to the electron transport.

${ }^{1}$ Present address: Department of Microbiology, University of Connecticut Health Center, Formington, Connecticut 06032, U.S.A. 
Recently, an increasing accumulation of experimental evidences (3-10) indicates that chemiosmotic phenomena, as postulated by Mitchell (11-14), play a central role in respiration-linked active transport in $E$. coli membrane vesicles. The oxidation of electron donors in the vesicles results in the generation of a transmembrane electrical potential (interior negative) by means of electron extrusion $(5-10)$. The potential is postulated to drive solute accumulation via facilitated diffusion of positively charged substrates such as lysine or via coupled movements of protons with neutral substrate such as serine (i.e., symport).

The results presented in this paper show that lipid A, fatty acids, and their derivatives act as proton conductors of membrane vesicles, and the electrical potential produced by electron transport systems or by $\mathrm{K}^{+}$-diffusion via valinomycin was abolished. This appears to be the reason why neither succinate nor amino acids can be accumulated by membrane vesicles in the presence of these compounds. It has also been found that the inhibition of transport activities by lipid A and fatty acids is partially recovered by the addition of bovine serum albumin.

\section{MATERIALS AND METHODS}

Preparation of membrane vesicles and lipid A. The cells of E. coli W 2252 were grown in a nutrient broth medium supplemented with $0.2 \%$ succinate (15) and the membrane vesicles were prepared according to the method described by MuraKawa et al. (15), which was almost similar to that of KABACK (16). Lipid A from Salmonella typhimurium TV 119 was prepared as described previously (1).

Uptake studies. a) Respiration-linked active transport. The uptake of succinate and amino acids was measured as described previously (1). Uptake of triphenylmethylphosphonium ion $\left(\mathrm{TPMP}^{+}\right)$was assayed similarly to that of amino acids with the exceptions of using ${ }^{3} \mathrm{H}$-triphenylmethylphosphonium bromide $(0.4 \mathrm{mM}, 0.304 \mu \mathrm{Ci})$ instead of ${ }^{14} \mathrm{C}$-amino acid, a Millipore EHWP filter (5) instead of HAWP filter, and $50 \mu \mathrm{l}$ total volume instead of $100 \mu \mathrm{l}$. Where indicated, bovine serum albumin was added at $10 \mathrm{~min}$ of the preincubation, the samples were incubated for another $5 \mathrm{~min}$, and then the transport assay was carried out as described above.

b) Amino acid uptake by artificial membrane potential. Potassium-loaded vesicles were prepared according to the method of HiRATA et al. (8). The uptake of ${ }^{14} \mathrm{C}$-serine by potassium-loaded vesicles was assayed by the method essentially identical to that of HiRATA et al. (7), where $1 \mathrm{mg}$ of potassium-loaded membrane vesicles was diluted to $500 \mu \mathrm{l}$ final volume containing, in final concentrations,

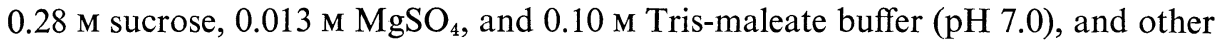
additions as indicated. The samples in small test tubes were preincubated at $25^{\circ}$ for $15 \mathrm{~min}$. Where indicated, bovine serum albumin was added as described before. The reaction was started by the addition of valinomycin $(2 \mu \mathrm{g}$ in $2 \mu 1$ of 
ethanol) to each sample. ${ }^{14} \mathrm{C}$-Serine $(15.6 \mu \mathrm{M}, 0.65 \mu \mathrm{Ci})$ was added just before the addition of valinomycin. At various periods, 50- $\mu$ l aliquots of the suspension were withdrawn, filtered through a Millipore HAWP filter, and washed once with $5 \mathrm{ml}$ of $0.4 \mathrm{M}$ sucrose containing $0.01 \mathrm{M} \mathrm{MgSO}_{4}$. Sampling and washing were completed within $15 \mathrm{sec}$. The filter was immediately removed from the suction apparatus to a glass counting vial, and the radioactivity was measured as described previously (1).

Proton permeability of membrane vesicles. Proton permeability of membrane vesicles was measured by the method essentially identical to that of PATEL et al. (4), where $28 \mathrm{mg}$ protein of the membrane preparations was diluted in a centrifuge tube to $14 \mathrm{ml}$ final volume containing, in final concentrations, $0.05 \mathrm{M}$ potassium phosphate buffer ( $\mathrm{pH}$ 6.6), $0.01 \mathrm{M} \mathrm{MgSO}_{4}$, and other additions as indicated. The samples were preincubated at $25^{\circ}$ for $15 \mathrm{~min}$, and then centrifuged and washed once with $0.66 \mathrm{M} \mathrm{KCl}$ containing $2.0 \mathrm{~mm}$ potassium phosphate buffer ( $\mathrm{pH} \mathrm{6.6).} \mathrm{Where}$ indicated, bovine serum albumin was added after $10 \mathrm{~min}$ from the start of the preincubation. The pellets were resuspended in the same medium at protein concentration of $28 \mathrm{mg} / \mathrm{ml}$, and valinomycin was added to a final concentration of $15 \mu \mathrm{M}$. The rates of proton equilibration were measured as follows; 1-ml aliquots of the suspensions were transferred to a tube and were continuously mixed with a small magnetic stirrer. The $\mathrm{pH}$ was measured by a $\mathrm{pH}$ meter (Model HM-208, Toa Electronics Ltd., Tokyo) equipped with a glass electrode (Type GS-195, Toa Electronics Ltd., Tokyo). The resulting signal was recorded in a strip chart recorder (Model 056, Hitachi Ltd., Tokyo). The profile of $\mathrm{pH}$ changes was monitored after a rapid addition of $40 \mu \mathrm{l}$ of $0.1 \mathrm{~N} \mathrm{HCl}$ by a microsyringe.

Labeled compounds. Succinic acid $\left[2,3-{ }^{14} \mathrm{C}\right](18 \mathrm{mCi} / \mathrm{mmol}), \mathrm{L}$-alanine $\left[\mathrm{U}-{ }^{14} \mathrm{C}\right]$ $(17 \mathrm{mCi} / \mathrm{mmol})$, DL-leucine $\left[1-{ }^{14} \mathrm{C}\right](51.5 \mathrm{mCi} / \mathrm{mmol})$, and myristic acid[1- $\left.{ }^{14} \mathrm{C}\right]$ $(45 \mathrm{mCi} / \mathrm{mmol})$ were purchased from the Daiichi Pure Chemicals Co., Tokyo. L-Serine[U- $\left.{ }^{14} \mathrm{C}\right](168 \mathrm{mCi} / \mathrm{mmol})$, and glycine[U- $\left.{ }^{14} \mathrm{C}\right](114 \mathrm{mCi} / \mathrm{mmol})$ were purchased from the Japan Radioisotope Association, Tokyo. Triphenylmethylphosphonium[U- $\left.{ }^{3} \mathrm{H}\right]$ bromide $(114 \mathrm{mCi} / \mathrm{mmol})$ was a generous gift from Dr. $\mathrm{H}$. Ronald Kaback of the Roche Institute of Molecular Biology, Nutley, N.J., U.S.A.

\section{RESULTS}

\section{Restoration of transport activities by bovine serum albumin}

The effect of bovine serum albumin on the transport activities which had been inactivated by lipid A or fatty acids was studied. Membrane vesicles were preincubated with lipid A or fatty acids at $25^{\circ}$ for 10 min to inactivate the transport activities. They were then incubated with bovine serum albumin for $5 \mathrm{~min}$ at $25^{\circ}$ and subjected to the assay of transport activities. Figure 1 shows the effect of bovine serum albumin on the succinate transport activity poisoned by myristic acid. 
Bovine serum albumin at $18 \mathrm{mg} / \mathrm{ml}$ restored the transport activity to approximately $75 \%$ of that of the control membrane vesicles which were not treated with the fatty acid. Bovine serum albumin restored the succinate transport activity which was inhibited not only by myristic acid but also by lipid A as shown in Table 1 . Table 2 shows the recovery of amino acid transport activities in myristic acid-treated membrane vesicles by bovine serum albumin. Although bovine serum albumin itself stimulated amino acid transport activities significantly, a remarkable recovery was observed with the myristic acid-treated vesicles in the presence of bovine serum albumin.

Table 1. Reactivation of succinate uptake by bovine serum albumin.

\begin{tabular}{ccccc}
\hline $\begin{array}{c}\text { Addition } \\
\text { of } \\
\text { bovine serum albumin } \\
(18 \mathrm{mg} / \mathrm{ml})\end{array}$ & Control & $\begin{array}{c}\text { Uptake of succinate } \\
\text { with lipid A A } \\
(0.08 \%)\end{array}$ & $\begin{array}{c}\text { with myristic acid } \\
(0.88 \mathrm{~mm})\end{array}$ & $\begin{array}{c}\text { Inhibition } \\
(\%)\end{array}$ \\
\cline { 2 - 5 } & 96 & 18 & - & 81 \\
\hline- & 98 & - & 10 & 90 \\
\hline+ & 69 & - & 30 \\
& & - & 74 & 24 \\
\hline
\end{tabular}

Table 2. Effect of myristic acid and bovine serum albumin on uptakes of various amino acids.

\begin{tabular}{|c|c|c|c|c|}
\hline \multirow[b]{2}{*}{ Substrate } & \multirow{2}{*}{$\begin{array}{l}\text { Addition } \\
\text { of } \\
\text { bovine serum } \\
\text { albumin } \\
(18 \mathrm{mg} / \mathrm{ml})\end{array}$} & \multicolumn{3}{|c|}{$\begin{array}{c}\text { Uptake } \\
(\mathrm{pmol} / \mathrm{mg} \text { protein } / \mathrm{min})\end{array}$} \\
\hline & & $\begin{array}{l}\text { without } \\
\text { myristic acid }\end{array}$ & $\begin{array}{c}\text { with } \\
\text { myristic acid } \\
(0.88 \mathrm{~mm})\end{array}$ & $\begin{array}{l}\text { Inhibition } \\
(\%)\end{array}$ \\
\hline \multirow[t]{2}{*}{ Serine } & - & 135 & 11 & 92 \\
\hline & + & 258 & 89 & 66 \\
\hline \multirow[t]{2}{*}{ Alanine } & - & 56 & 5 & 91 \\
\hline & + & 173 & 97 & 44 \\
\hline \multirow[t]{2}{*}{ Glycine } & - & 68 & 4 & 94 \\
\hline & + & 183 & 86 & 53 \\
\hline \multirow[t]{2}{*}{ Glutamate } & - & 44 & 1 & 98 \\
\hline & + & 61 & 61 & 0 \\
\hline \multirow[t]{2}{*}{ Leucine } & - & 6 & 1 & 83 \\
\hline & + & 18 & 10 & 44 \\
\hline \multirow[t]{2}{*}{ Phenylalanine } & - & 15 & 7 & 53 \\
\hline & + & 29 & 22 & 24 \\
\hline
\end{tabular}

Binding of fatty acid to membrane vesicles and its removal by bovine serum albumin

Membrane vesicles were incubated at $25^{\circ}$ with various amounts of ${ }^{14} \mathrm{C}$ myristic acid. After 10 min the mixture was centrifuged to sediment membrane vesicles and radioactivities in the supernatant and the precipitate were counted. As shown in Fig. 2, the amount of myristic acid bound to the membrane vesicles 

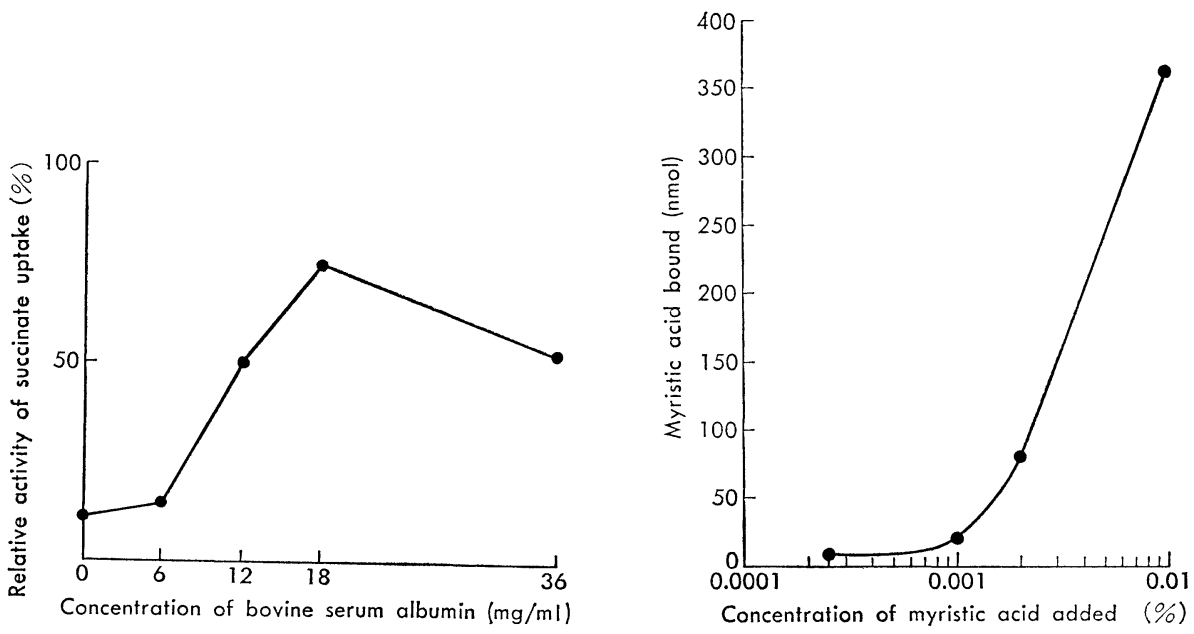

Fig. 1. Effect of bovine serum albumin on the restoration of myristic acid-inactivated succinate transport.

Membrane vesicles were pretreated with myristic acid $(0.88 \mathrm{~mm})$ and various concentrations of bovine serum albumin were included as described in the MATERIALS AND METHODS. The uptakes of succinate were then measured.

Fig. 2. Binding of myristic acid to membrane vesicles.

One $\mathrm{mg}$ protein of the membrane preparation was diluted to $0.5 \mathrm{ml}$ final volume containing, in final concentrations, $0.05 \mathrm{M}$ potassium phosphate buffer $(\mathrm{pH} 6.6), 0.01 \mathrm{M}$ $\mathrm{MgSO}_{4}$, and various concentrations of ${ }^{14} \mathrm{C}$-myristic acid $(45 \mu \mathrm{Ci} / \mathrm{mmol})$ as indicated. The samples were preincubated at $25^{\circ}$ for $10 \mathrm{~min}$. The mixture was centrifuged to precipitate membrane vesicles and the radioactivities in the supernatant and precipitate were counted.

was roughly proportional to the logarithmic concentration of myristic acid added. The addition of bovine serum albumin to the membrane vesicles treated with myristic acid resulted in an almost complete removal of the fatty acid from the membrane vesicles (Table 3 ).

Table 3. Removal of myristic acid from membrane vesicle by bovine serum albumin.

\begin{tabular}{cccc}
\hline & \multicolumn{3}{c}{${ }^{14}$ C-Myristic acid } \\
\cline { 2 - 3 } $\begin{array}{c}\text { Bovine serum albumin } \\
(18 \mathrm{mg} / \mathrm{ml})\end{array}$ & Radioactivity & (c.p.m.) & $\begin{array}{c}\text { Membrane bound } \\
(\%)\end{array}$ \\
\cline { 2 - 3 } & Supernatant & Membrane & \\
\hline- & 9,930 & 24,780 & 71.4 \\
+ & 32,990 & 2,100 & 6.0 \\
\hline
\end{tabular}

${ }^{14} \mathrm{C}$-myristic acid $(0.88 \mathrm{~mm}, 0.0185 \mu \mathrm{Ci})$ was incubated as described in Fig. 2 , except that bovine serum albumin was added $10 \mathrm{~min}$ after the beginning of incubation, and the samples were incubated for another $5 \mathrm{~min}$. The mixture was centrifuged to sediment membrane vesicles and the radioactivities in the supernatant and precipitate were counted. 
Effects of lipid A, fatty acids, and their derivatives on the uptake of triphenylmethylphosphonium ion $\left(\right.$ TPMP $\left.{ }^{+}\right)$

As shown in Fig. 3, when lauric acid, myristic acid, and oleic acid, which are a potent inhibitor of succinate transport (1-2), were added to the membrane vesicles, they inhibited the generation and/or maintenance of a membrane potential as judged by the inability of the membrane vesicles to catalyze the uptake of the lipophilic cation, ${ }^{3} \mathrm{H}-\mathrm{TPMP}^{+}$. When bovine serum albumin was added to the myristic acid-treated membrane vesicles, partial recovery in $\mathrm{TPMP}^{+}$uptake was observed (Fig. 3). Addition of bovine serum albumin to the control membranes

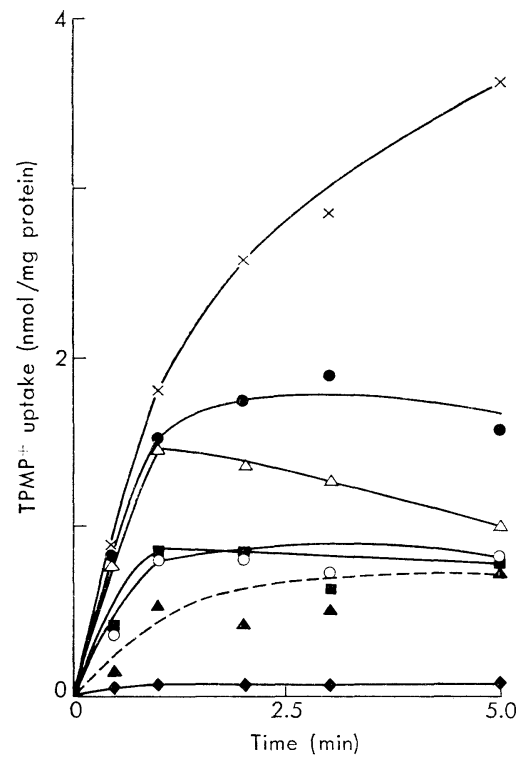

Fig. 3. Effect of lipid A, fatty acids and their derivatives on the uptake of triphenylmethylphosphonium ion $\left(\mathrm{TPMP}^{+}\right)$.

Membrane vesicles were preincubated with lipid A $(0.08 \%)(\mathrm{O}-\mathrm{O})$, myristic acid, lauric acid, oleic acid or lauryl alcohol $(-\downarrow)$, myristic acid and then bovine serum albumin $(1.8 \%)(\mathbf{\Delta - - \Delta})$, methyl laurate $(\boldsymbol{\square}-\mathbf{\square})$, stearic acid $(\Delta-\Delta)$, bovine serum albumin $(1.8 \%)(\times-\times)$, and no addition $(-\bullet)$.

The concentration of fatty acids and their derivatives was $0.88 \mathrm{~mm}$ in $2 \%$ dimethyl sulfoxide. The control contained the same amount of dimethyl sulfoxide.

stimulated $\mathrm{TPMP}^{+}$uptake. Lipid A, one of the potent inhibitors of succinate transport (1-2), inhibited the uptake of TPMP ${ }^{+}$although to a lesser extent (Fig. 3). Lauryl alcohol, which is a potent inhibitor of serine and other amino acid transports (data not shown), severely inhibited $\mathrm{TPMP}^{+}$uptake. Methyl laurate, which is a moderate inhibitor, partially inhibited $\mathrm{TPMP}^{+}$uptake. Stearic acid, which has no significant effect on succinate transport, did not affect $\mathrm{TPMP}^{+}$uptake. 
Effect of lipid $A$, fatty acids and their derivatives on proton permeability of membrane vesicles

Since any defect resulting in the increased ion permeability could abolish the ability of the vesicles to generate and/or maintain the electrical potential, permeability of the vesicles to proton was investigated. As shown in Fig. 4 and

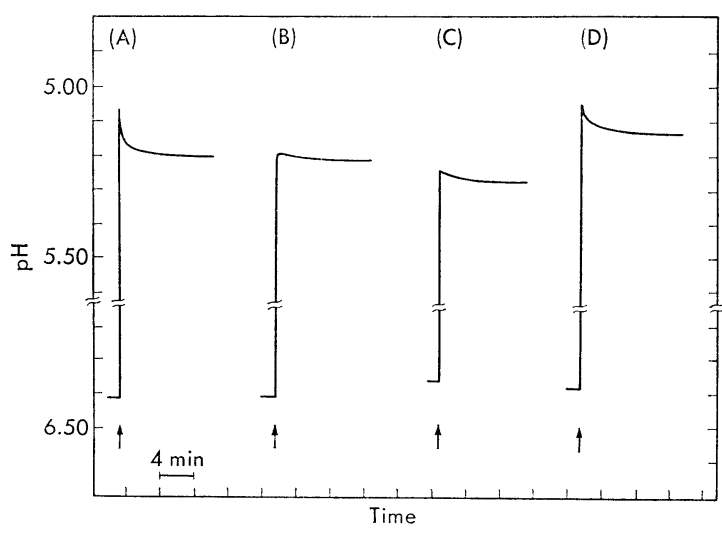

Fig. 4. Effect of myristic acid and bovine serum albumin on proton permeability of $E$. coli membrane vesicles.

(A) Control membrane vesicles. (B) Membrane vesicles containing carbonylcyanide $m$-chlorophenylhydrazone $(0.1 \mathrm{mM})$. (C) Membrane vesicles treated with myristic acid $(0.88 \mathrm{~mm})$. (D) Myristic acid-treated membrane vesicles incubated in the presence of bovine serum albumin $(18 \mathrm{mg} / \mathrm{ml})$.

At the time indicated by the arrows, the samples were pulsed with $\mathrm{HCl}$, the $\mathrm{pH}$ decreased rapidly, reached its minimum point, and then increased due to the permeation of proton across the membrane vesicles. Finally, $\mathrm{pH}$ values reached the steady state within 3-4 $\mathrm{min}$.

Table 4, myristic acid, lauric acid, and oleic acid, which are potent inhibitors of succinate transport system (1-2), markedly enhanced the proton permeability when the membrane vesicles were pretreated with these compounds. Lipid A, lauryl alcohol, and methyl laurate, which are inhibitors of succinate transport, also enhanced the proton permeability. When the membrane vesicles pretreated with a fatty acid were treated with bovine serum albumin, the relative proton permeability was reduced from 3.50 to 1.56 as shown in Table 4 . Stearic acid or bovine serum albumin slightly reduced the proton permeability of membrane vesicles.

Effect of lipid $A$, fatty acids, and their derivatives on amino acid uptake by artificial membrane potential

As shown above, lipid A, fatty acids, and their derivatives inhibited TPMP ${ }^{+}$ uptake and enhanced proton permeability. These results may indicate that they 
Table 4. Effect of lipid A, fatty acids and their derivatives on proton permeability of membrane vesicles.

\begin{tabular}{lccc}
\hline \multirow{2}{*}{ Additions } & $\begin{array}{c}\text { Concentration } \\
(\mathrm{mM})\end{array}$ & \multicolumn{2}{c}{ Proton permeability } \\
\cline { 3 - 4 } & - & $\Delta \mathrm{pH}$ & $\begin{array}{c}\text { Relative } \\
\text { proton permeability }\end{array}$ \\
\hline None & $0.08 \%$ & 0.14 & 1.00 \\
Lipid A & 0.88 & 0.08 & 1.75 \\
Lauric acid & 0.88 & 0.05 & 2.80 \\
Myristic acid & 0.88 & 0.04 & 3.50 \\
Stearic acid & 0.88 & 0.17 & 0.82 \\
Oleic acid & 0.88 & 0.05 & 2.80 \\
Methyl laurate & 0.88 & 0.07 & 2.00 \\
Lauryl alcohol & & 0.06 & 2.33 \\
Carbonylcyanide & & & \\
$\quad m$-chlorophenylhydrazone & 0.10 & 0.03 & 4.67 \\
Bovine serum albumin & $1.8 \%$ & 0.17 & 0.82 \\
Myristic acid & 0.88 & & 1.56 \\
$\quad$ plus bovine serum albumin & $1.8 \%$ & 0.09 & \\
\hline
\end{tabular}

$\triangle \mathrm{pH}$ represents $\mathrm{pH}$ at the minimum point $-\mathrm{pH}$ at the steady state (see Fig. 4). Relative proton permeability represents $\Delta \mathrm{pH}$ of control membrane vesicles $/ \Delta \mathrm{pH}$ of membrane vesicles treated with indicated compound. Each compound, except bovine serum albumin, was dissolved in dimethyl sulfoxide $(2 \%)$ and added to the reaction mixture.

Table 5. Effect of lipid A, fatty acids and their derivatives on serine uptake by artificial membrane potential.

\begin{tabular}{lccc}
\hline \multirow{2}{*}{ Additions } & $\begin{array}{c}\text { Concentration } \\
(\mathrm{mM})\end{array}$ & \multicolumn{2}{c}{ Serine uptake } \\
\cline { 3 - 4 } & & pmol/mg protein & Inhibition (\%) \\
\hline None & $0.08 \%$ & 30 & - \\
Lipid A & 0.88 & 17 & 43 \\
Lauric acid & 0.88 & 0 & 100 \\
Myristic acid & 0.88 & 23 & 100 \\
Stearic acid & 0.88 & 0 & 23 \\
Oleic acid & 0.88 & 19 & 100 \\
Methyl laurate & 0.88 & 3 & 37 \\
Lauryl alcohol & & & \\
Carbonylcyanide & 0.10 & 0 & 100 \\
$\quad m$-chlorophenylhydrazone & 0.88 & 37 & -123 \\
Myristic acid & $1.8 \%$ & 64 & -213 \\
$\quad$ plus bovine serum albumin & $1.8 \%$ & & \\
Bovine serum albumin & & &
\end{tabular}

Minus indicates stimulation.

As soon as valinomycin was added to the sample, uptake of serine occurred and reached maximum at $15 \mathrm{sec}$, and then declined gradually. The data shown in this table are the values of serine uptake at $15 \mathrm{sec}$, after addition of valinomycin. 
act as proton conductors of membrane vesicles. If this is the case, lipid A, fatty acids, and their derivatives should inhibit the transport activity driven by the artificial membrane potential introduced by $\mathrm{K}^{+}$-diffusion via valinomycin. As shown in Table 5, the uptake of serine driven by an artificial membrane potential was severely inhibited by lauric acid, myristic acid, oleic acid, and laury alcohol, which act as potent proton conductors of membrane vesicles (Fig. 3 and Table 4), and bovine serum albumin partially recovered the serine uptake. Addition of bovine serum albumin alone stimulated serine uptake. The moderate proton conductors, lipid A and methyl laurate, partially inhibited the serine uptake. Stearic acid, which is not a proton conductor, showed little effect on serine uptake.

\section{DISCUSSION}

In the preceding papers $(1-2)$, we have shown that lipid A, fatty acids, and their derivatives inhibited the accumulation of succinate or amino acids (serine, glycine, alanine, and leucine) which coupled to the electron transport. The results shown in Fig. 1 and Tables 1, 2, and 3 indicated that the inhibition of transport activities of membrane vesicles by fatty acids was due to the binding of these inhibitors to the membrane vesicles, and the inhibition was reversible if the inhibitor was removed by the addition of bovine serum albumin. Therefore, the possibility that lipid A or fatty acid solubilized the membrane components to form "holes" and thus, membranes no longer had the capacity to retain succinate or amino acids, should be excluded. In fact, glucose transport occurred normally even in the presence of lipid A or fatty acids (1-2).

The stimulation of amino acid transport activities by bovine serum albumin was in agreement with the results reported by Mizushima (17). Recently, OHTA et al. (18) reported that the alteration in phospholipid composition of membrane vesicles from $E$. coli resulted in the altered transport activities of amino acids. Therefore, it is possible that the altered transport activities of membrane vesicles treated with bovine serum albumin were due to alteration in the phospholipid composition.

There are several lines of evidence demonstrating that certain fatty acids act as proton conductors of membrane vesicles: (1) Fatty acids enhanced the proton permeability of membrane vesicles. (2) Uptake of $\mathrm{TPMP}^{+}$by the membrane vesicles was inhibited by fatty acids. (3) Serine uptake by an artificial membrane potential introduced by $\mathrm{K}^{+}$-diffusion via valinomycin was inhibited by fatty acids, and the proton potential (interior negative) produced by electron transport systems or by $\mathrm{K}^{+}$-valinomycin was abolished. Heaton and Nicholis (19) reported that endogenous fatty acid in mitochondria act as a proton conductor, and their observation was consistent with our conclusion presented here. The effect of fatty acids on the proton conductivity of membrane vesicles was partially recovered by the addition of bovine serum albumin. Fatty alcohol, lipid A, and methylated fatty 
acid seem also to act as weak proton conductors. Lipid A was a potent inhibitor of succinate and amino acid transport systems (1-2), while it was not a potent proton conductor. Therefore, the inhibition mechanism of succinate and amino acid transport systems by lipid A should be partly due to its action as a proton conductor, partly due to its inhibition of respiration (1-2), and, perhaps, partly due to other targets which have not been elucidated as yet.

PATEL et al. (4) reported that the treatment of the membrane vesicles from $E$. coli with chaotropic agents abolished the membrane potential which could be reversed by the addition of N,N'-dicyclohexylcarbodiimide (DCCD). Since the amino acid transport activities of the fatty acid-treated membrane vesicles could not be reversed by DCCD (data not shown), the target of fatty acids seems to be different from that of the chaotropic agents.

We are grateful to the late Prof. Tsutomu Watanabe of the School of Medicine, Keio University, for his generous supply of Salmonella typhimurium TV119 used in this experiment. We are particularly grateful to Dr. H. Ronald Kaback of the Roche Institute of Molecular Biology, Nutley, N. J., U.S.A., for his generous supply of ${ }^{3} \mathrm{H}$-triphenylmethylphosphonium bromide used in this experiment. We also thank Miss Kumiko Saito of this Faculty for her help in the radioassays.

\section{REFERENCES}

1) J.-S. Lai, S. Okuda, H. Abe, and H. Takahashi, J. Gen. Appl. Microbiol., 22, 85 (1976).

2) J.-S. Lai, S. Okuda, and H. Takahashi, Amino Acid and Nucleic Acid, 33, 49 (1976), in Japanese.

3) H. R. KaBACK, Science, 186, 882 (1974).

4) L. Patel, S. Schuldiner, and H. R. Kaback, Proc. Natl. Acad. Sci. U.S.A., 72, 3387 (1975).

5) S. Schuldiner and H. R. KABACK, Biochemistry, 14, 5451 (1975).

6) J. P. Reeves, Biochem. Biophys. Res. Commun., 45, 931 (1971).

7) H. Hirata, K. Altendorf, and F. M. Harold, Proc. Natl. Acad. Sci. U.S.A., 70, 1804 (1973).

8) H. Hirata, K. Altendorf, and F. M. Harold, J. Biol. Chem., 249, 2939 (1974).

9) K. Altendorf, H. Hirata, and F. M. Harold, J. Biol. Chem., 250, 1405 (1975).

10) S. Ramos, S. Schuldiner, and H. R. Kaback, Proc. Natl. Acad. Sci. U.S.A., 73, 1892 (1976).

11) P. Mitchell, Nature, 191, 144 (1967).

12) P. Mitchell, Biol. Rev. Cambridge Philos. Soc., 47, 445 (1966).

13) P. Mitchell, J. Bioenerg., 4, 63 (1973).

14) F. M. Harold, Bacteriol. Rev., 36, 172 (1972).

15) S. Murakawa, K. Izaki, and H. Takahashi, Agric. Biol. Chem. (Tokyo), 37, 1905 (1973).

16) H. R. Kaback, J. Biol. Chem., 243, 3711 (1968).

17) S. Mizushima, Biochim. Biophys. Acta, 419, 261 (1976).

18) T. OHta, S. Okuda, and H. TAKahashi, Biochim. Biophys. Acta, 466, 44 (1977).

19) G. M. Heaton and G. Nicholis, Eur. J. Biochem., 67, 511 (1976). 